\title{
FILOSOFIA UBUNTU
}

\author{
Francisco Antonio de Vasconcelos \\ Professor Adjunto II da Universidade Estadual \\ do Piauí. Pós-doutorando em Ciências da \\ Religião. \\ franciscoantonio_vasconcelos@yahoo.com.br
}

\begin{abstract}
Resumo
A presente pesquisa tem por objetivo refletir sobre alguns dos principais aspectos de Ubuntu, aqui considerado como uma das várias correntes da filosofia africana. A metodologia empregada neste trabalho caracteriza-se por ser de cunho qualitativo. Com efeito, trata-se de uma pesquisa bibliográfica cujo corpus compõe-se de literatura especializada. Esta investigação se justifica, considerando-se que a sociedade contemporânea é marcada, dentre outras coisas, por um individualismo e egocentrismo excessivos além de uma valorização da matéria em detrimento do humano. A filosofia Ubuntu, que se traduz em "Eu sou, porque nós somos", possui um potencial ético capaz de fortalecer um convívio social, no qual valores como a solidariedade, a confiança, o respeito, a generosidade são assumidos como fundamentais. Este trabalho investigativo chegou às seguintes conclusões: a filosofia Ubuntu representa uma das contribuições mais originais da filosofia africana; o potencial ético dessa corrente filosófica não deve ser desprezado pela filosofia brasileira; considerando que Brasil e África precisam aprender a pensar de modo descolonizado, é fato que os filósofos africanos estão mais comprometidos com essa tarefa do que os brasileiros, sendo a corrente filosófica Ubuntu um testemunho disso.
\end{abstract}

Palavras-chave: Ubuntu. Pensamento ético-político. Filosofia africana.

\section{UBUNTU PHILODOPHY}

\begin{abstract}
The present research aims to reflect on some of the main aspects of Ubuntu, considered here as one of several currents of African philosophy. The methodology used in this work is characterized by being qualitative. In fact, it is a bibliographical research whose corpus is composed of specialized literature. This research is justified considering that contemporary society is marked, among other things, by an excessive individualism and selfcenteredness and an appreciation of matter to the detriment of the human. The Ubuntu philosophy, which translates to "I am, because we are", has an ethical potential capable of strengthening social interaction, in which values such as solidarity, trust, respect, generosity are assumed as fundamental. This investigative work came to the following conclusions: the Ubuntu philosophy represents one of the most original contributions of the African philosophy; The ethical potential of this philosophical current should not be neglected by Brazilian philosophy; Considering that Brazil and Africa need to learn to think in a decolonized way, it is a fact that the African philosophers are more committed to this task than the Brazilians, being the current philosophical Ubuntu a testimony of this.
\end{abstract}

Key-words: Ubuntu. Ethical-political thinking. African philosophy.

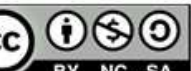

Esta obra está licenciada sob uma Licença Creative Commons Atribuição 4.0 Internacional (CC BY-NC-AS 4.0).

LOGEION: Filosofia da informação, Rio de Janeiro, v. 3 n. 2, p. 100-112, mar./ ago. 2017. 


\section{Considerações iniciais}

Umuntu ngumuntu ngabantu (“Uma pessoa é uma pessoa através de outras pessoas”) é um provérbio dos Zulus que ilustra bem o espírito da filosofia Ubuntu. Este típico modo de pensar e de agir está presente em boa parte do continente africano, pertencendo aos povos bantu. Esta designação resulta da predominância de um determinado grupo linguístico na região. "Existe no continente africano uma diversidade imensa de línguas e de culturas, sendo que podemos reconhecer neste conjunto uma unidade cultural. Unidade esta que Diop (DIOP, 1990) denomina como a unidade na diversidade". (ROCHA JUNIOR, 2010, p. 84).

Ubuntu aponta para uma existência marcada pela convivência harmoniosa com o Outro. Dessa forma, o espírito que dá vida a essa filosofia traduz-se em respeito que se converte na valorização do humano (muntu) e da natureza (kintu). Tratar-se-ia, nas palavras de Frans Tempels, de "uma filosofia sem filósofos". Numa época em que a capacidade filosófica dos povos bantu era colocada em xeque, o pensador belga, que viveu boa parte de sua vida como missionário católico, na região do antigo Congo Belga, advoga a tese contrária, apresentando argumentos para demonstrar a existência de um pensar filosófico elaborado por eles. Infelizmente, a história testemunha o seguinte fato: "Dado ao desconhecimento ocidental, às vezes acidental noutras proposital (BERNAL, 1987), grande parte do conhecimento da humanidade não existe como conhecimento racional”. (ROCHA JUNIOR, 2010, p. 83).

Contudo, felizmente, cresce o número de autores do Ocidente que percebem a presença do pensamento filosófico no continente africano. É o caso da filósofa alemã Anke Graneß. Em seu modo de ver, no que se refere à filosofia africana, deve-se esperar uma grande pluralidade de tradições filosóficas. Além disso trata-se de um fenômeno dinâmico (GRANEß, 2013). A filosofia Ubuntu é uma das ramificações da filosofia africana.

\footnotetext{
Com o Ubuntu operou-se a mudança da concepção da identidade a partir do 'eu sou porque tu não és' (concepção excludente) para o 'eu sou porque nós somos, e dado que somos então eu sou' (concepção includente)". Desta maneira objetiva, mas contundente, Jean Bosco Kakozi Kashindi demonstra um dos principais deslocamentos teóricos e práticos da racionalidade do continente africano em relação ao olhar ocidental hegemônico. Em entrevista por e-mail à IHU On-Line, ele explica que a filosofia africana oferece elementos para pensar, também, a realidade latinoamericana e caribenha. (MACHADO, 2015).
}

Fechando essas primeiras considerações, afirmamos com Ramose que a ética derivada da filosofia Ubuntu assenta-se numa sólida base filosófica.

\subsection{Filosofia Ubuntu}


Traduzir Ubuntu para a linguagem ocidental, certamente, não é coisa fácil. Este conceito diz respeito à essência do ser humano. Quando desejamos ofertar nosso mais alto apreço a alguém, dizemos: "Yu, u nobuntu" ("Ei, ele ou ela tem Ubuntu”). Isto significa que a pessoa é generosa, hospitaleira, amigável, atenciosa e compassiva. Ela compartilhou o que possuía. Significa também que minha humanidade foi alcançada, está inextrincavelmente ligada a da outra pessoa. Nós pertencemos a uma mesma força vital. A pessoa é humana porque pertence, participa, compartilha. Alguém com Ubuntu á aberta e acessível aos outros. (TUTU, 1999 apud VAN NIEKERK, 2013, p. 1).

$\mathrm{Na}$ concepção do arcebispo anglicano Desmond Tutu, que presidiu a Truth and Reconciliation Commission (TRC), Ubuntu é um conceito onipresente no discurso público sulafricano. O termo se refere a uma constelação de reivindicações de valor e exigências moralmente normativas ostensivamente extraídas da psicologia folclórica tradicional da África do Sul. (VAN NIEKERK, 2013, p. 1).

Van Niekerk diz que seu trabalho Ubuntu and Moral Value tem três objetivos: a) Argumentar que a dificuldade existente na explicação do Ubuntu não é intrínseca ao conceito em si, mas à função de um jogo de linguagem paralisado, que não precisa se aplicar às investigações filosóficas. Isto é suportado pela congruência do Ubuntu com termos cognatos e discussões paralelas na filosofia africana de forma mais geral. $\mathrm{O}$ autor acrescenta que o trabalho sobre Ubuntu qua teoria moral deveria levar em conta precedentes na filosofia africana de forma mais ampla; b) Pesquisar a história e a metodologia da filosofia africana, tendo em vista as preocupações e os desafios característicos que a moldaram e são pertinentes ao desenvolvimento do Ubuntu; c) Aplicar as lições relevantes da filosofia africana à literatura filosófica existente sobre o Ubuntu. (VAN NIEKERK, 2013, p. 2)

O filme In My Country (Em minha terra) procura mostrar o trabalho de dois jornalistas (Langston Whitfield e Anna Malan) presentes na África do Sul pós-apartheid para fazer a cobertura dos depoimentos, nas Comissões de Verdade e Reconciliação, instituídas pelo governo de Mandela. Nele, há uma cena, na qual temos um encontro entre os personagens Whitfield, Anna e o ancião. A conversa que se estabelece ali serve para explicar o significado de Ubuntu, isto é, "Cada um de nós é parte do outro". Essa assertiva ajuda a entender ainda melhor o espírito de Ubuntu. Ela esclarece o sentido do "Eu", nessa corrente filosófica africana. Ele é incompreensível sem a figura do "Outro". Sua constituição ocorre a partir desse "Outro". Devemos lembrar, conforme foi posto acima, quem é o "Outro". Trata-se tanto da outra pessoa (muntu) quanto da própria natureza (kintu). Há também um provérbio do povo xhosa que 
reforça essa compreensão. Ele diz: "Cada humanidade individual se expressa idealmente na relação com os demais". Portanto, fica claro que a filosofia Ubuntu aponta para a intersubjetividade, mas uma subjetividade em profunda sintonia e dependência com a natureza.

[...] partir do outro como ponto de partida ético — vale a redundância — é então considerar que vivemos em um mundo, em uma sociedade, que é, parafraseando Tempels, como uma rede, onde não se pode mover um fio sem que os outros se movam. Com outras palavras, já não há a necessidade de demonstrar que dependemos não apenas dos outros seres humanos, mas também de outras entidades cósmicas (ar, água, montanhas, árvores, minerais, animais, etc.) que nos possibilitam viver. Negligenciar o Outro é, na perspectiva do Ubuntu, desumanizar-se. Urge, pois, sair ao encontro desse Outro, reconhecê-lo e construir com ele uma solidariedade afetiva, calorosa, como a própria etimologia da ética indica. (MACHADO, 2015).

Sem dúvida alguma, como esclarece objetivamente a citação acima, quando nos esquecemos do Outro, nós nos desumanizamos. Em meu modo de entender, reside aqui a força do potencial ético-político dessa corrente filosófica. Segundo Ramose, Ubuntu liga-se epistemologicamente a umuntu ${ }^{1}$. O autor procura esclarecer:

umuntu postula ubuntu como sua categoria normativa básica da ética. Kagamé sugere corretamente que muntu ${ }^{2}$, kintu, hantu e kuntu são as quatro categorias da filosofia africana. Porém, a enumeração não é completa nem suficiente sem a inclusão de ubuntu. Ubuntu é a quinta categoria básica da filosofia africana. É a categoria ética normativa que prescreve e, portanto, deve permear a relação entre muntu, kintu, hantu, e kuntu". (2002, p. 1).

Para entender um pouco melhor essas categorias - nada simples, mas fundamentais vejamos a explicação abaixo:

Nas línguas africanas as existências do mundo material e imaterial podem ser agrupadas em um número de pelo menos quatro categorias. São classificações linguísticas. Estas quatro categorias básicas de tudo que existe é bem explicita nas línguas bantu e podem ser nomeadas como: MUNTU, para os seres humanos completos, KINTU, para as coisas animadas e inanimadas consideradas todas como portadores de vida, HANTU, representando tudo que tem relação com tempo e espaço, KUNTU, como modalidade ou como os atributos de inter-relação de categorias, como uma força que permite a ligação entre dois significados. (KAGAME, 1956 apud ROCHA JUNIOR, 2010, p. 87-88).

\footnotetext{
${ }^{1}$ Pode ser traduzida como "pessoa". Ramose informa: "uтипtu libera a fala do ser e persegue sua racionalidade através do diálogo", dado ser capaz de consciência de si (2002, p. 2). Equivale, a uma só vez, a homo loquens e homo sapiens. A política, lei e a religião são obras suas.

2 "Muntu é a pessoa, constituída pelo corpo, mente, cultura e principalmente, pela palavra". (ROCHA JUNIOR, 2010, p. 81)
} 
Para Kagamé, o "movimento é o princípio do ser, entendido como "ser-sendo". Assim, conforme Ramose, Ubuntu está de acordo com essa ideia de ser como movimento. Trata-se, na verdade, do prefixo $u b u$ - (geral) e a raiz -ntu (específico). Ele explica: "Ubu- como ser-sendo encoberto está sempre orientado em direção ao descobrimento[...]. Ubu- e -ntu não são duas realidades radicalmente separadas e irreconciliavelmente opostas". De acordo com Ramose, elas formam uma totalidade indivisível. ${ }^{3}$ (2002, p. 3).

Mas, é preciso esclarecer melhor o sentido de "-ntu”. Vejamos a explicação que segue:

\begin{abstract}
NTU é a força do universo, que sempre ocorre ligada a sua manifestação em alguma coisa existente no campo material ou do simbólico ou do espiritual, nomeados nas formas de muntu, kintu, hantu e kuntu. O NTU embora não existe por si próprio, ele transforma a tudo que existe com elementos tendo uma mesma natureza em comum. Tudo tem o seu NTU. O NTU não expressa a força da natureza em si, mas a sua existência. Importante que Deus é a única categoria a parte que não tem necessidade de se expressar pelo NTU. O Deus é único é não é um NTU, mas os ancestrais e Inquices são parte de um dado NTU. O NTU é uma expressão de energia. Tudo é composta da combinação ou transformações da energia em qualidades diversas. Cada categoria tem um NTU em determinada qualidade ou modalidades. (ROCHA JUNIOR, 2010, p. 87).
\end{abstract}

O autor nos dá ainda as seguintes informações a respeito de "-ntu”: ele é o princípio responsável pela existência de todas as coisas.

$\mathrm{Na}$ verdade, trata-se aqui de uma racionalidade diferente daquela que construiu o Ocidente, caracterizada pela tendência a instrumentalizar seja a pessoa seja a natureza. Consideremos dois exemplos de seu potencial nefasto: contra a pessoa, citemos a colonização; contra a natureza, podemos mencionar o avanço científico-tecnológico.

Quanto à primeira, Césaire, em Discurso sobre o colonialismo, faz considerações mostrando que ela desumaniza. O autor lança críticas pesadas à Europa, condenando-a por ela ter pretendido ser a única a julgar os homens, a definir a partir de si mesma qual cultura presta e qual não possui valor. O pensador alerta para o fato de que o colonialismo é portador de racismo. Para o filósofo, o colonialismo desciviliza tanto o colonizado quanto o colonizador. Ele reclama do fato da Europa ter criado a colonização e não saber lidar com ela. Em sua concepção, para a colonizadora não há defesa. $\mathrm{O}$ autor sublinha que não é contrário colocar civilizações diferentes em contato, pois, com efeito, isso é algo que, em si, tende a ser positivo. O problema é que a colonização não era a melhor maneira de estabelecer o contato entre Europa e África/Américas. Entre colonizador e colonizado - diz ele - só há lugar para o trabalho

\footnotetext{
${ }^{3}$ Para as sociedades bantu, a categoria "totalidade" ocupa um lugar de destaque na constituição da visão de mundo desses povos. Para eles existe uma relação entre todas as coisas, que pode ser modificada pela ação dos muntu.
} 
forçado, pois a colonização gera a coisificação do colonizado (CESAIRE, 1978, p. 6-25).

A respeito do avanço científico-tecnológico, vale pedir auxílio ao filósofo alemão Hans Jonas. De modo simples, a questão é colocada por ele da seguinte forma: Em seu estágio atual, a humanidade experimenta um elevadíssimo grau de desenvolvimento científico-tecnológico jamais visto anteriormente. O problema, na visão do filósofo, consiste na incapacidade do homem em controlar, totalmente, os efeitos da aplicação dessa tecnologia. Para ele, essa falta de controle, coloca em risco a existência da própria espécie humana e o equilíbrio das forças da natureza responsável pela manutenção da vida no planeta. As modernas tecnologias podem fazer do homem um objeto de seu agir.

As éticas tradicionais dizem respeito ao imediato 4 . Para ele, "nenhuma ética anterior tinha de levar em consideração a condição global da vida humana, o futuro distante e até mesmo a existência da espécie" (JONAS, 2006). Outro ponto interessante trazido à baila por Jonas diz respeito ao fato de que a cultura ocidental sempre comportou uma ética antropocêntrica e simétrica, que abarca apenas as relações entre as pessoas.

Essa nova racionalidade se caracteriza por ser humanista. Todavia, vale ressaltar o fato desse humanismo ser compreendido adequadamente somente se considerarmos, como foi colocado acima, que a existência da pessoa, considerada individualmente, está condicionada a existência das outras pessoas e da natureza. Trata-se, portanto, de um tipo de racionalidade que leva a agir sempre considerando o Outro (muntu e kintu) como um ser ontologicamente próximo. Em relação a esse Outro, ela exige o respeito, a responsabilidade e a capacidade de abrir mão de certos interesses pessoais em benefício do bem dele.

\section{Algumas características da sociedade contemporânea}

A racionalidade europeia, ao contrário, é egocêntrica, optou por sobrepor o "Eu" ao "Nós". Essa escolha, ao longo da história ocidental, materializou-se na forma de dominação. Com efeito, a Europa aparece marcada pelo desejo de subjugar a tudo e a todos. Isso pode ser observado no caso do Império Romano, cuja ânsia por expandir suas fronteiras parecia insaciável; na Igreja qua instituição que concentrou em suas mãos o poder temporal e espiritual, na Idade Média; na própria ciência moderna, que entendeu a natureza como algo totalmente objetivo (externo ao homem) a ser dominado por este; no capitalismo, que reduz as outras

\footnotetext{
${ }^{4}$ Lamentavelmente, ao fazer essa afirmação, o filósofo europeu considera apenas a tradição ocidental relativa à filosofia moral.
} 
pessoas a instrumento de lucro; assim como na colonização e no racismo dela decorrente.

Esse tipo de racionalidade construiu a sociedade contemporânea.

Zygmunt Bauman $(2005,2007)$ compreende nossa sociedade como "modernidade líquida”. Isto significa defini-la como o conjunto de relações e instituições, além de sua lógica de operações, que se impõe e que dão base para a contemporaneidade. É uma época de liquidez, de fluidez, de volatilidade, de incertezas e insegurança. É nesta época que toda a fixidez e todos os referenciais morais da época anterior são retirados de cena. O espaço deixado será preenchido pela lógica do agora, do consumo, do gozo e da artificialidade.

A sociedade contemporânea apresenta, dentre outras, as seguintes características:

- Globalização: Sobre a globalização, não podemos deixar de citar Manuel Castells (1999), que assinala vários acontecimentos históricos os quais têm transformado a paisagem social da vida humana, tais como: a desagregação do bloco soviético e as mudanças de políticas econômicas nas nações de regimes socialistas, pondo fim à guerra fria e a reestruturação profunda do capitalismo.

- Tecnologização: Nossa sociedade é marcada pelo avanço tecnológico. Para Castells, uma das características da globalização é a capacidade ou falta de capacidade das sociedades para dominar a tecnologia e em particular as que são estrategicamente decisivas em cada período histórico, define em boa parte seu destino. De acordo com Hans Jonas, o avanço tecnológico atingiu um nível tal que a humanidade já não é capaz de controlar as consequências do uso dessa tecnologia, pondo em risco o equilíbrio do planeta e a existência da própria espécie humana.

- Conhecimento: Por uns a sociedade contemporânea é denominada "sociedade de informação"; por outros, "sociedade do conhecimento" ou "do aprendizado". O fato é que o conhecimento desempenha, na atualidade, papel estratégico. Esse desenvolvimento cognitivo só foi possível graças ao paradigma da ciência moderna, assentado na razão, na divisão/análise e na máxima "conhecer para controlar".

-Atomização: O estilo de vida da contemporaneidade é marcado cada vez mais pelo isolamento. A exclamação de Nietzsche "o deserto cresce" (1993, p. 41) expressa o sentimento de quem está diante de uma determinada dinâmica de civilização e presencia um momento importante deste processo de desertificação. O deserto da sociedade contemporânea é pensado como o resultado de uma dinâmica na qual o homem moderno entende sua identidade na razão direta de sua capacidade de dominar a natureza e os outros homens.

- Consumismo: Fruto do desenvolvimento do capitalismo, o consumismo é outra característica de nossa sociedade. Quando o mercado determina o estilo de vida de uma 
sociedade e as ações do Estado, o consumo aparece como uma consequência necessária, transformando tudo e todos em objeto de consumo (educação, religião, saúde, lazer, conhecimento, etc, e o próprio ser humano).

- Crise identitária: De acordo com Bauman, nossa época é marcada por uma crise de identidade cujos traços podem vir em forma de uma falta de identidade, identidade múltiplas ou identidade fragmentada.

- Crise de moraliade: Anthony Giddens (2002) aponta para um certo empobrecimento moral, uma certa crise de valores, uma certa crise de moralidade. E ao lado de um alto grau de reflexividade social, surge uma preocupação com a reconstrução da tradição como uma forma de enfrentar as demandas cambiantes das sociedades modernas. A reconstrução da tradição pode ser observada, por exemplo, na busca, cada vez mais intensa, de novas experiências religiosas, novas formas de espiritualidade.

Infelizmente, podemos acrescentar ainda a essa lista a injusta, a tendência a sobrepor os bens materiais ao ser humano, a adoção de um estilo de vida egoísta/egocêntrico, a insistência em recorrer à violência como estratégia para a solução de conflitos, por exemplo.

\section{Ubuntu: uma ética-política}

Na Grécia Antiga, ética e política andavam juntas. Eram elementos indissociáveis somente podendo ser compreendidos, adequadamente, à luz da vida na polis. Com o advento da modernidade, o Ocidente, que há muito tempo havia se distanciado da polis grega e aprendera, durante a Idade Média, a lidar com as esferas da ética e da política através da categoria "fé", experimentou a disjunção dessas duas áreas. Todavia, no século XIX, com a crítica de Karl Marx ao capitalismo, ficam expostas as mazelas para o indivíduo e para a sociedade de se ter optado por separar ética e política. Mas, foi, sobretudo, Hannah Arendt quem se dedicou a mostrar, por meio de sua filosofia política, quão funesta foi para o Ocidente, e para toda a humanidade, essa decisão. A partir daí, muitos são os autores ocidentais dedicados a elaborar sistemas éticos-políticos, no campo da filosofia moral.

Neste tópico, apresentamos Ubuntu como um exemplo de ética-política presente na tradição africana e fruto da racionalidade que rege, há milênios, a vida dos povos daquele continente.

No século XVIII, os autores ligados ao pensamento iluminista colocaram em evidência as teses da emancipação e da igualdade entre as pessoas. Contudo, elas pareciam valer apenas 
para o europeu, pois ao mesmo tempo em que elas eram proclamadas, a Europa continuava a manter, de modo violento, o jugo sobre os ombros dos índios e negros em suas colônias. Entretanto, o debate suscitado por elas vai, no século XIX, conduzir ao tema da possibilidade ou não do africano elaborar um pensar filosófico. Em 1944, o missionário católico Placide Frans Tempels publicou o livro A Filosofia bantu do ser ${ }^{5}$. Através dessa obra, ele procura demonstrar que os povos daquela região possuem um pensamento filosófico.

\begin{abstract}
[Tempels] pôde demonstrar que os bantu tinham uma ontologia, uma metafísica, uma epistemologia, uma psicologia, uma ética e uma religião baseadas na concepção do ser como força. Esta concorre sempre para procurar a vida. Tempels observou que os bantu se relacionavam com outros seres, animados ou inanimados, com vistas a fortalecer sua vida ou diminuir a força vital de um inimigo. Isto quer dizer que a ontologia bantu dista da ontologia clássica ocidental, que considera o ser enquanto ser. Para os bantu, o ser é força, ou melhor dito, é força vital, porque existe uma relação intrínseca entre "força" e "vida". Desde esta ótica, o ser é sempre concretamente dinâmico; expressa-se como força, a mesma que é a exteriorização da energia e, por conseguinte, está sempre em relação ativa com a vida para aumentá-la e, às vezes, diminuí-la. Esta foi a principal crítica de Tempels, sobre a qual fundamentou todo o edifício da filosofia africana bantu. Após o trabalho do missionário belga, houve críticas a favor ou contra que foram situadas em diferentes correntes da filosofia africana: a corrente ontológica, chamada também de "etnofilosofia"; a refutação do "tempelsianismo" (Fabien Eboussi-Boulaga), a destruição da "etnofilosofia" (Marcien Towa e Paulin Hountondji); Crítica da crítica da "etnofilosofia", entre outras. Embora estas correntes tenham aberto o fazer filosófico africano, foi o trabalho pioneiro de Tempels que influenciou e propulsou todos os trabalhos posteriores. Em suma, a filosofia africana bantu foi uma reflexão crítica reivindicativa de um tributo eminentemente humano que é a razão. Se os africanos têm uma ontologia diferente, uma ética diferente, metafísica... infere-se que possuem uma racionalidade diferente da ocidental. (MACHADO, 2015).
\end{abstract}

De fato, a filosofia Ubuntu tem suas raízes fincadas no conceito "Força Vital".

Que Nelson Mandela, o Tata Madiba - como é carinhosamente chamado pelos sulafricanos - teve um papel ímpar na luta de independência da África do Sul, tornando-se um personagem dos mais marcantes do campo político, no século passado, não é nenhuma novidade, evidentemente. Talvez, para alguns seja desconhecido o papel desempenhado pela filosofia Ubuntu, em seu engajamento político. Com efeito, podemos afirmar ser Ubuntu um dos princípios fundadores da África do Sul.

Ainda no campo político, podemos dizer que existe uma relação intrínseca entre Ubuntu e a tradição de valorização do consenso, encontrada em várias regiões do continente africano. A este respeito, considere-se o caso dos povos akan estudado por Kwasi Wiredu. Este pensador, membro dos Ashantis, há anos investiga a experiência consensual vivenciada por esses povos,

\footnotetext{
${ }^{5}$ Aquilo que o Ocidente nomeia de "Ser" o povo bantu chama de "Força Vital". Ela representa para essa gente o único valor fundamental.
} 
os quais habitam boa parte do território de Gana.

Nesse contexto em que se busca chegar a um consenso nas questões políticas, emergem os conselhos como elementos políticos ímpares, entre os Ashantis. Isto decorre do fato desses povos manterem a crença de que os interesses de todos os membros da sociedade são os mesmos. Assim, podemos assegurar:

\footnotetext{
Sem dúvida, abunda nas sociedades africanas localizadas ao sul do Saara a experiência Ubuntu. Essa experiência é elemento fundamental na constituição da cosmovisão dos povos bantu, influenciando, portanto, várias esferas dessas sociedades, inclusive a política. Nesta, Ubuntu é utilizado para enfatizar a necessidade da união entre todos e da busca por consenso nas tomadas de decisão, assumindo-se uma ética humanista. (VASCONCELOS, no prelo).
}

O sentido que Desmond Tutu dá ao termo Ubuntu advém dessa compreensão eticopolítica do conceito. Para o religioso ativista, Ubuntu quer dizer, sobretudo, "eu sou, porque nós somos".

O termo "Nós" aplica-se, evidentemente, à outra pessoa (muntu), tanto a nível individual quanto coletivo, apontando para uma existência amparada pela intersubjetividade. Contudo, o "Nós" também pode se referir à natureza (kintu). Neste caso, ele indica que não há existência para a pessoa humana senão uma existência situada através da natureza. Dito de outra forma: o ser humano é com a natureza. Isto implica em afirmar que agredir, desrespeitar e colocar em risco a pessoa humana e/ou a natureza significa negar Ubuntu e agir de modo contrário à sua ética.

De fato, com a filosofia Ubuntu aprendemos que os elementos formadores da natureza (todos eles animados) possuem a função de melhorar e perpetuar a vida. "A cultura e a religião assim como todas as instituições e habilidades humanas têm o mesmo objetivo: reforçar a vida e superar qualquer perigo que a ameace. A ética bantu se define em referência a essa mesma finalidade." (BURGOS, 2016).

O professor Augustine Shutte, em Ubuntu: An ethic for a New South Africa, obra na qual discute o potencial ético de Ubuntu, assim se manifesta: "É um conceito ético e expressa uma visão do que é valioso e do que vale a pena na vida. Essa visão está enraizada na história da África e está no centro da cultura da maior parte dos sul-africanos". Prosseguindo em sua reflexão, o escritor faz questão de destacar, em prol da tese, notoriamente defendida por ele, de acordo com a qual Ubuntu, compreendido como filosofia de vida, pode e deve ser assumido por todos os povos do planeta. Sobre isso ele diz: "Mas os valores que ela [a ética Ubuntu] contém não estão somente na África. Eles são valores da humanidade enquanto tal e, portanto, universais". (SHUTTE, 2001, p. 10). 
Contudo, é preciso considerar que Ubuntu não é um simples humanismo. Certamente, não se limita ao humanismo europeu do século XVI, pois o supera. “A organização das línguas Bantu reflete a organização de uma filosofia do ser humano, da coletividade humana e da relação destes seres com a natureza e o universo". (ROCHA JUNIOR, 2010, p. 81).

\section{Considerações Finais}

África e Brasil possuem muito em comum. Entretanto, há um elemento que merece ser sublinhado: partilham o fato de terem sido colônias da Europa. Essa experiência histórica as colocou na periferia do mundo. O artigo Filosofia africana na disciplina Filosofia da Educação chama a atenção para um aspecto que não deve ser passado despercebido na história da filosofia África, isto é, o papel desempenhado pela luta dos africanos em prol da emancipação do jugo imposto pelo ocidente (VASCONCELOS, no prelo).

Nesse mesmo texto, chamo a atenção do leitor para o fato do processo de construção da sociedade brasileira, expressão da racionalidade europeia, ter sido marcado por um equívoco: a matriz branca, assumindo o controle do processo, ao invés de procurar integrar as outras duas matrizes (índios e negros), ao contrário, despende uma enorme quantidade de esforços para negar aos povos indígenas, em um primeiro momento, e, posteriormente, a esses e aos povos negros, o direito a existirem como parte dessa sociedade.

Abdias do Nascimento em $O$ genocídio do negro brasileiro: Processo de um racismo mascarado insiste na necessidade da descolonização do pensar, ao tratar do tema do embranquecimento da raça (Capítulo V), da cultura (Capítulo IX) e ao discutir as reações ao embranquecimento, como é o caso do Teatro Experimental do Negro (Capítulo XIV), fundado no Rio de Janeiro em 1944 pelo próprio Abdias. Ele denuncia: "Dentro de um século, ou de três séculos, isto pouco importa; o que se fazia essencial e indisputável era a necessidade de embranquecer o povo brasileiro por dentro e por fora". (1978, p. 73).

Mas, afinal, estaria essa racionalidade ocidental, tão destrutiva, esgotada? Na visão de autores como Aimé Césaire, Franzt Fanon e V. Y. Mudimbe, a resposta é afirmativa. Aliás, Césaire expressa isso ao afirmar, de modo irretocável, que a "Europa é indefensável" (1978, p. 3). De acordo com o autor, o Ocidente não consegue dar conta de dois problemas criados por ele: o proletariado e a colonização. Esses dois são altamente desumanizadores, tendem a destruir o ser humano. Disto a história é testemunha.

Contudo, é preciso reconhecer que, nas últimas décadas, a própria Europa vem buscando novas formas de racionalidade. Um exemplo disso é a razão comunicativa de Jürgen Habermas assim como a ética da responsabilidade de Hans Jonas. Mas, o mundo espera mais do continente 
europeu, e de todo o Ocidente. Urge, para o bem da espécie humana e para a preservação da vida no planeta, uma abertura maior por parte do Ocidente a racionalidades como a representada por Ubuntu.

\section{Referências}

BAUMAN, Z. Identidade. Rio de Janeiro: Jorge Zahar Ed., 2005.

Modernidade líquida. Rio de Janeiro: Jorge Zahar Ed., 2007.

BURGOS, B. Filosofia africana. In: Blog Acadêmico. Madrid: África Fundación Sur, 2016. Disponível em:

<http://www.africafundacion.org/IMG/pdf/Bartolome_Bugos_FILOSOFIA_AFRICANA.pdf >. Acesso em: 13 out. 2016.

CASTELLS, M. A Sociedade em rede. São Paulo: Paz e Terra, 1999. 1 v. (A era da informação: economia, sociedade e cultura).

DIOP. C. A. The cultural unity of black africa. 5. ed. Chicago: Third World Press, 1990.

GIDDENS, A. Modernidade e identidade. Rio de Janeiro: Jorge Zahar Ed., 2002.

KAGAME, A. La philosophie Bantu-Rwandaise de l'Etre. Bruxelas: ARSC, 1956.

JONAS, H. O princípio responsabilidade: ensaio de uma ética para uma civilização tecnológica. Rio de Janeiro: PUC Rio, 2006.

CUNHA JÚNIOR, H. NTU. Revista Espaço Acadêmico, Maringá, n. 108, p.81-92, maio 2010. Disponível em:

<http://periodicos.uem.br/ojs/index.php/EspacoAcademico/article/viewFile/9385/5601>. Acesso em: 31 mar. 2017.

KASHINDI, J. B. K. Metafísicas africanas: eu sou porque nós somos. 2015. Disponível em: <http://www.ihu.unisinos.br/entrevistas/548478-metafisicas-africanas-eu-sou-porque-nossomos-entrevista-especial-com-jean-bosco-kakozi-kashindi>. Acesso em: 31 mar. 2017.

NASCIMENTO, A. O genocídio do negro brasileiro: processo de um racismo mascarado. Rio de Janeiro: Paz e Terra, 1978.

VAN NIEKERK, J. Ubuntu and Moral Value. 2013. 193 f. Tese (Doutorado em Filosofia) Faculdade de Humanidades, University of the Witwatersrand, Johannesburg.

NIETZSCHE, F. Ditirambos de Diónisos. Lisboa: Guimarães Editores, 1993.

RAMOSE, M. B. A ética do Ubuntu. In: COETZEE, P. H.; ROUX, A. P. J. (Ed.). The

African Philosophy Reader. New York: Routledge, 2002. p. 324-330. Tradução para uso didático por Éder Carvalho Wen. Disponível em: <http://filosofiaafricana.weebly.com/uploads/1/3/2/1/13213792/mogobe_b._ramose__a_ética_do_ubuntu.pdf >. Acesso em: 11 out. 2016.

SHUTTE, A. Cbuntu: an ethic for a New South Africa. Pietermaritzburg: Cluster Publications, 2001.

TEMPELS, P. F. La philosophie bantoue. Paris: Présence Africaine, 1945.

TUTU, D. No future without forgiveness. New York: Random House, 1999. 
Filosofia da Informação

VASCONCELOS, F. A. de (no prelo). Filosofia africana na disciplina Filosofia da Educação. In: $1^{\circ}$ Seminário Internacional de Educação em Direitos Humanos. Altos: ASSEBEPI.

VASCONCELOS, F. A. Filosofia africana na disciplina Filosofia da Educação. In: SEMINÁRIO INTERNACIONAL DE EDUCAÇÃO EM DIREITOS HUMANOS, 1., 2016, Altos. Anais... . No prelo.

Jürgen Habermas e Kwasi Wiredu: reflexões sobre o consenso. In: XII COLÓQUIO HABERMAS \& III COLÓQUIO DE FILOSOFIA DA INFORMAÇÃO, 12, 2016, Rio de Janeiro. Anais... . No prelo. 